\title{
Temperature and food sources influence subadult development and blood-feeding response of Culicoides obsoletus (sensu lato) under laboratory conditions
}

\author{
Claudia Van den Eynde ${ }^{*}$ (D) Charlotte Sohier ${ }^{\dagger}$, Severine Matthijs and Nick De Regge
}

\begin{abstract}
Background: Culicoides obsoletus (s.l.) is the most abundant Culicoides species in northern Europe and an important vector of bluetongue virus and Schmallenberg virus. Nevertheless, information on its subadult life stages remains scarce and no laboratory-reared colony exists.

Methods: C. obsoletus (s.l.) adults were collected in Belgium and transferred to the laboratory in an attempt to establish a laboratory-reared colony. C. obsoletus (s.l.) were reared from eggs to adults at different temperatures $\left(28^{\circ} \mathrm{C}, 24^{\circ} \mathrm{C}\right.$, $20 / 16^{\circ} \mathrm{C}$ ) and under different food regimes.

Results: The most suitable temperature for rearing seemed to be $24^{\circ} \mathrm{C}$ for most developmental parameters, but resulted in a biased 3:1 male/female sex ratio. The latter could be optimized to a 1:1 sex ratio when a $20 / 16^{\circ} \mathrm{C}$ day/ night temperature gradient was applied, but rearing at these low temperature conditions resulted in significantly lower egg hatching and pupation rates and a longer subadult development time. Independent of the rearing temperature, adding dung as an additional food source during larval development resulted in a significantly higher adult emergence rate and a decrease in subadult development time. Furthermore, blood-feeding rates of field-collected $C$. obsoletus (s.l.) were compared for different blood sources and feeding systems. The overall blood-feeding success was low and only successful with cotton pledgets ( $2.7 \%$ blood-fed midges) and through a membrane system with chicken skin (3.5\% blood-fed midges). Higher feeding rates were obtained on cattle blood compared to sheep blood.
\end{abstract}

Conclusions: These results will help us to determine the necessary conditions to rear a viable laboratory colony of this important vector species, although further optimization is still required.

Keywords: Biting midges, Colony, Vector, Arbovirus, Artificial blood-feeding

\section{Background}

Culicoides obsoletus Meigen and Culicoides scoticus Downes and Kettle are the most abundant and widespread Culicoides species (Diptera: Ceratopogonidae) in northern Europe [1-3] and the most important vectors

*Correspondence: claudia.vandeneynde@sciensano.be

${ }^{+}$Claudia Van den Eynde and Charlotte Sohier share the first authorship Sciensano, Enzootic, Vector-Borne and Bee Diseases, Groeselenberg 99

1180 Brussels, Belgium of Schmallenberg virus [4] and bluetongue virus [5] in Europe. Both viruses cause serious economic losses to the livestock (cattle, sheep and goats) industry. Since morphological distinction between $C$. obsoletus and $C$. scoticus females is not straightforward, both species are considered together as C. obsoletus (s.l.). They belong to the subgenus Avaritia, together with Culicoides chiopterus and Culicoides dewulfi. original author(s) and the source, provide a link to the Creative Commons licence, and indicate if changes were made. The images or other third party material in this article are included in the article's Creative Commons licence, unless indicated otherwise in a credit line to the material. If material is not included in the article's Creative Commons licence and your intended use is not permitted by statutory regulation or exceeds the permitted use, you will need to obtain permission directly from the copyright holder. To view a copy of this licence, visit http://creativecommons.org/licenses/by/4.0/. The Creative Commons Public Domain Dedication waiver (http://creativeco mmons.org/publicdomain/zero/1.0/) applies to the data made available in this article, unless otherwise stated in a credit line to the data. 
C. obsoletus (s.l.) has four larval instars [6] and can overwinter as fourth-instar larvae in diapause [7], indicating that temperature has an influence on larval molting [8] and growth [9]. C. obsoletus (s.l.) larvae usually inhabit the top few centimetres of moist and highly organic soil substrates (e.g. old, composted manure mixed with soil) usually without freestanding water [6]. C. obsoletus (s.l.) is an anautogenous species which implies that newly emerged females are not capable of maturing eggs when given sugar solution alone and need a blood meal for this.

Despite the importance of C. obsoletus (s.l.) as vectors of important veterinary disease agents, no laboratory colonies of C. obsoletus (s.l.) exist, resulting in very limited information on the life cycle traits of this species, particularly of subadult life stages. Two previous studies described the development from egg to adult on agar for C. obsoletus, and reported low survival [10] and biased development towards the production of males [11]. The obstacles to establishing a colony of C. obsoletus (s.l.) and related species include their reluctance to mate under laboratory conditions [12, 13], high mortality of fieldcaught midges [14], limited knowledge on their larval nutrition and larval substrates [12] and a reluctance of field-collected females to blood feed under laboratory conditions through artificial blood-feeding systems [12, 15 .

The majority of studies of Culicoides-arbovirus interactions have been conducted using laboratory lines of Culicoides sonorensis infected with either bluetongue virus or the closely related African horse sickness virus $[6,13$, $16]$. Because this species is relatively large, possesses a rapid life cycle and mates in confined cages under laboratory conditions, it is more straightforward to work with. However, the degree to which the mechanisms of vector competence in $C$. sonorensis are representative of other Culicoides vector species is unknown [13]. Therefore, additional research on blood-feeding under laboratory conditions has been conducted with field-collected C. obsoletus (s.l.), despite their unpredictable availability, using natural and artificial membranes [14, 17-20] with the aim of improving laboratory blood-feeding in order to perform vector competence studies and to attempt to establish a laboratory colony. Existing blood-feeding techniques for C. obsoletus (s.l.) employ cotton pledgets and a heating system with different membranes, namely chicken skin, Parafilm, Nescofilm and collagen. Differences in feeding rates have been reported depending on the blood-feeding technique, blood source, days of acclimatization and days of starvation before blood-feeding [17].

The aim of our study was to improve our understanding of subadult development and the requirements to establish a viable laboratory colony of C. obsoletus (s.l.) by (i) evaluating the effect of different combinations of temperature and larval substrates on subadult development and emergence patterns of eggs laid by field-collected midges; and (ii) comparing different methods for artificial blood-feeding of Belgian C. obsoletus (s.l.)

\section{Methods \\ Collection of Culicoides}

Culicoides were collected at cattle and sheep farms in Belgium where abundant C. obsoletus (s.l.) populations have been found during previous surveillance studies [4, 21]. Culicoides were collected with Onderstepoort Veterinary Institute blacklight traps $(220 \mathrm{~V} ; 8 \mathrm{~W}$; Onderstepoort, SA), installed outside at $1.5-2 \mathrm{~m}$ above ground level, and identified with the Culicoides identification key [22]. Culicoides were collected on several nights between the end of April and the end of October 2018, 2019 and 2020. The Onderstepoort Veterinary Institute traps were modified with a cage $(17.5 \mathrm{~cm} \times 17.5 \mathrm{~cm} \times 17.5 \mathrm{~cm}$; BugDorm-41515; MegaView Science, Taichung, Taiwan) to store the live midges (Fig. 1) and a quarter of a biologically farmed apple was provided to avoid desiccation and as a food source. Traps were operated from 7 p.m. to $8 \mathrm{a} . \mathrm{m}$. and the cages were transferred to the laboratory immediately thereafter to reduce mortality. Once in the laboratory, the piece of apple was removed and a petri dish (Corning; diameter $\times$ height $100 \mathrm{~mm} \times 15 \mathrm{~mm}$ )

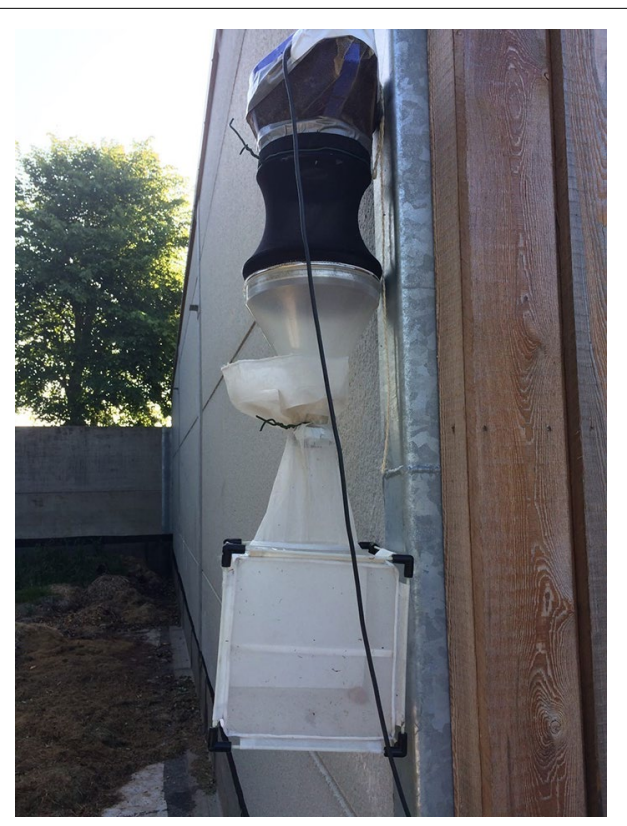

Fig. 1 Onderstepoort Veterinary Institute traps modified with a cage $(17.5 \mathrm{~cm} \times 17.5 \mathrm{~cm} \times 17.5 \mathrm{~cm}$; BugDorm-41515; MegaView Science, Taichung, Taiwan) to store the live midges 
containing a patch of cotton wool (Hartmann Watte; Hartmann, Belgium) soaked in $10 \%$ sucrose water [18, 23,24 ] with a filter paper (Whatman; 110-mm diameter, no. 1001 110) on top was provided as the food source. A second petri dish with a cotton pad soaked in water with a filter paper on top was provided as the oviposition substrate. The Culicoides were kept at $24{ }^{\circ} \mathrm{C}, 80 \%$ humidity and 16-8 h light-dark cycle [25].

\section{Subadult rearing procedures}

The development of subadult life stages was studied at three temperature conditions, namely $28^{\circ} \mathrm{C}, 24^{\circ} \mathrm{C}$ and a $20 / 16^{\circ} \mathrm{C}$ day/night temperature gradient, i.e. $16^{\circ} \mathrm{C}$ during the 8-h dark (night) period and a temperature increase/ decrease rate of $0.27{ }^{\circ} \mathrm{C} / \mathrm{min}$ at the beginning and end of the 8-h period. A temperature of $28^{\circ} \mathrm{C}$ was selected since it has been shown to result in shorter development times and a higher number of offspring of field-caught Culicoides (Avaritia) imicola Kieffer females [12]. To better mimic the temperature conditions of northern Europe, $24{ }^{\circ} \mathrm{C}$ and a day/night gradient of $20 / 16{ }^{\circ} \mathrm{C}$ were also tested.

The standard substrate for the subadult rearing consisted of a plastic petri dish filled with $10 \mathrm{ml}$ of $1 \%$ liquid broth agar medium [LB Agar, powder (Lennox L agar); Thermo Fisher Scientific, Belgium]. Standard additional food sources for the larvae were provided three times a week and consisted of about $2 \mathrm{mg}$ of the small freeliving nematode Panagrellus redivivus (acquired from the New Brussels Aquarium, Belgium), maintained on oatmeal (Quaker, Chicago, IL), and $1 \mathrm{ml}$ of the algae Chlamydomonas reinhardtii (colony provided by the Department of Plant Biotechnology and Bioinformatics, Ghent University, Belgium), grown in Tris-acetate-phosphate medium in 300-ml flask cultures [26]. P. redivivus were reared in plastic boxes on a layer $(1 \mathrm{~cm})$ of wet oatmeal. $P$. redivivus were removed directly from the sides of the container, a method adapted from Mullens and Velten [27]. At the $24{ }^{\circ} \mathrm{C}$ and $20 / 16{ }^{\circ} \mathrm{C}$ rearing condition (RC), we also studied the effect of adding patches of horse dung to the standard substrate. Horse dung was first maintained at $-20{ }^{\circ} \mathrm{C}$ for $48 \mathrm{~h}$ to ensure that all arthropods in the material were killed. A clump of $\sim 3 \mathrm{~g}$ was incorporated into the solidifying agar medium.

Finally, five RCs were compared for subadult development: standard substrate (1\% liquid broth agar with nematodes and algae) at $28{ }^{\circ} \mathrm{C}(\mathrm{RC} 1)$; standard substrate at $24{ }^{\circ} \mathrm{C}(\mathrm{RC} 2)$; standard substrate with additional horse dung patches at $24{ }^{\circ} \mathrm{C}$ (RC3); standard substrate at a $20 / 16^{\circ} \mathrm{C}$ day/night temperature gradient (RC4); and standard substrate with additional horse dung patches at a $20 / 16{ }^{\circ} \mathrm{C}$ day/night temperature gradient (RC5).
Eggs were laid by Culicoides females that had already blood-fed when collected in the field during the active vector seasons of 2018, 2019 and 2020. After oviposition, the filter paper with eggs was transferred to petri dishes containing the larval substrates described above. If more than 50 eggs were obtained at a specific time point, they were divided between the different RCs. At least 20 repetitions were conducted for each condition. Eggs from 2018 and 2019 were used to study RCs $1-3$, while eggs from 2020 were used to study RCs 4 and 5. Since egg batches were mostly limited and the egg hatching rate was low under several conditions, calculating means over the different repeats was not meaningful, and all results per RC were aggregated. Culicoides development was followed for 2 months from oviposition onwards and all rearing was performed in an environmental chamber (Panasonic MLR-352H Series; Thermo Fisher Scientific, Belgium) at a $16-8 \mathrm{~h}$ light-dark regime and $80 \%$ humidity. The day of oviposition of the eggs was designated as day 1 . The eggs were counted, placed under a specific $\mathrm{RC}$ and observed daily under a stereomicroscope (Zeiss Stemi 508; Zeiss, Belgium) to follow emergence from the eggs and further subadult development. After completion of the fourth larval instar life stage, C. obsoletus (s.l.) larvae become pale brown pupae (Fig. 2). Pupae were carefully removed from the agar and placed on a moist filter paper on top of a wet cotton wool pad in a container covered with a net, in which they could hatch into adults. The following developmental parameters were recorded: egg hatching rate, larval survival rate (i.e. survival of firstinstar larvae, estimated based on the number of hatched eggs, to fourth-instar larvae), pupation rate (i.e. development from fourth-instar larvae to pupae), pupal stage duration, adult emergence rate (i.e. development from pupae to adults) and sex ratio of the emerging adults. Emerged adults were immediately identified and sexed under the stereomicroscope after immobilization with $\mathrm{CO}_{2}$.

\section{Blood collection}

Defibrinated blood of sheep and cattle was used for blood-feeding. Defibrination was done following the method of Van der Saag [28]. Fresh blood was collected from cattle and sheep in the slaughterhouse in a flask $(2 \mathrm{~L})$ containing 3 layers of glass beads $(5-\mathrm{mm}$ diameter, borosilicate; Sigma-Aldrich, Belgium). Immediately upon collection, a gradual swirling motion of the beads was begun by hand at room temperature and continued until defibrination of the blood was complete $(5 \mathrm{~min})$. This was indicated by the formation of white foam (fibrin) on top of the blood. Once completed, the defibrinated blood was decanted into sterile screw-top containers $(50 \mathrm{ml})$ and stored at $4{ }^{\circ} \mathrm{C}$. 


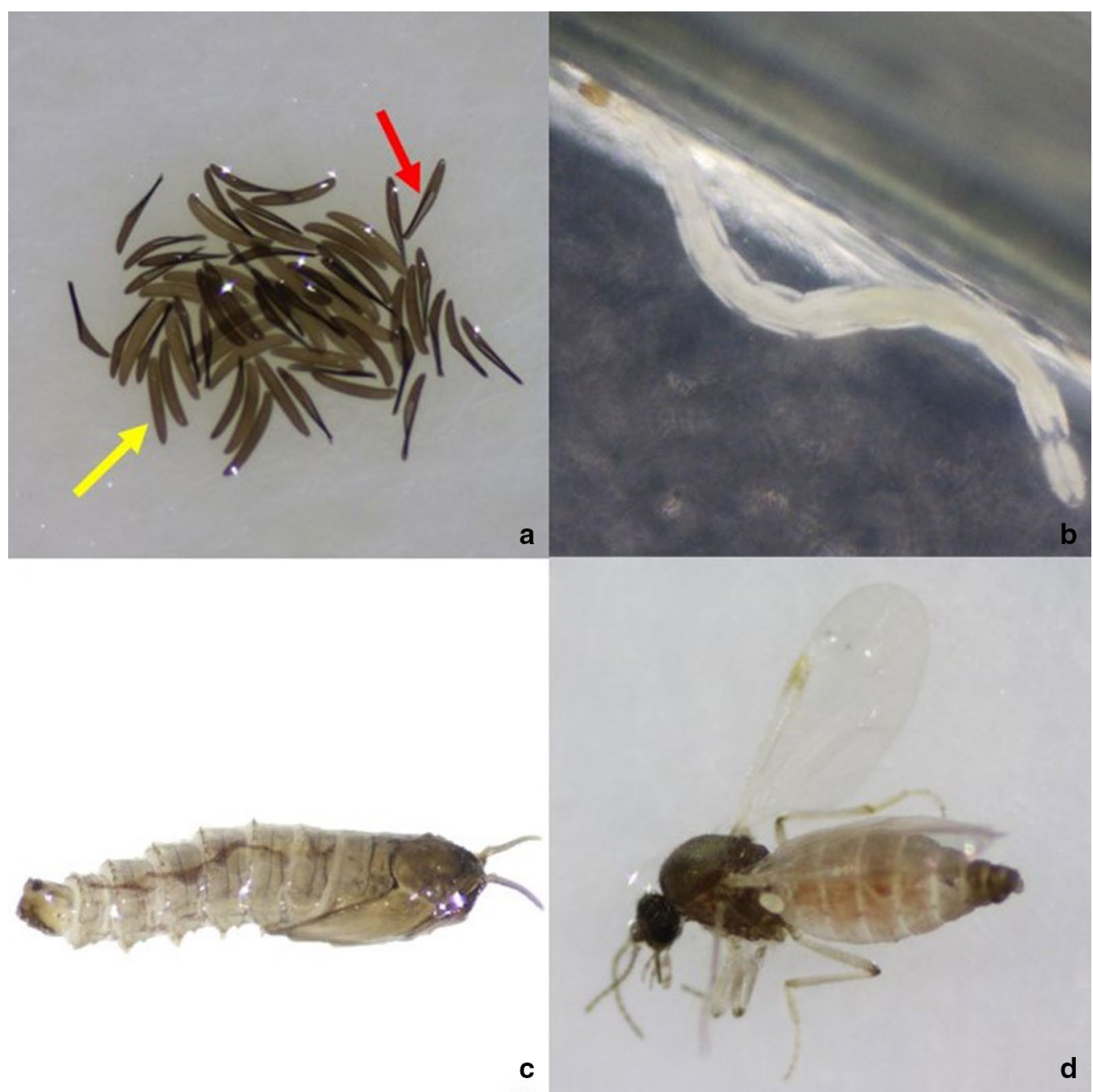

Fig. 2 Different developmental stages of Culicoides obsoletus (s.l.): hatched (red arrow) and unhatched (yellow arrow) eggs (a), fourth-instar larvae (b), pupa (c) and adult female (d)

\section{Culicoides blood-feeding}

In a separate experiment, Culicoides were collected for blood-feeding studies and housed in the laboratory as described above. Three days post-collection, the midges were starved for 1 day. At day 5, before placing them into a feeding chamber $\left(200 \mathrm{~cm}^{3}\right)$, the live midges were briefly immobilized with $\mathrm{CO}_{2}$ to allow species identification and verification of the absence of a previous blood meal (i.e. engorged). Blood of different origins (sheep or cattle blood) and several blood-feeding systems (cotton pledgets soaked in blood [14, 15] and membrane feeding systems) were evaluated. Membrane feeding systems included a stretched Parafilm M membrane (Bermis, USA) or chicken membrane (euthanized 1-day-old chickens were provided by Avian virology and immunology, Sciensano, following national and European regulations, procedure agreement 101105-02, from which the skin was subsequently removed-stretched-and most of the feathers removed) $[19,29,30]$ mounted on the bloodfeeding system with the feathered side on the inside of the feeding chamber as described by Venter et al. [29] (Fig. 3) or a collagen membrane (Hemotek Feeding Membrane; Hemotek, Blackburn, UK) mounted on the Hemotek system (Hemotek). In the blood-feeding system described by Venter, the blood meal was kept at $37{ }^{\circ} \mathrm{C}$ and agitated using a magnetic stirrer (Fig. 3). The feeding chamber consisted of a 40-mm-diameter 50-mm-high plastic bottle. The bottom of the bottle was replaced by the membrane (Parafilm or chicken membrane). The top of the bottle was cut out and replaced by gauze netting [36]. The blood source was placed on the bottom.

The blood meal mounted on the Hemotek system was also kept at $37{ }^{\circ} \mathrm{C}$ during feeding. The feeding chamber consisted of a 40-mm-diameter 50-mm-high plastic 


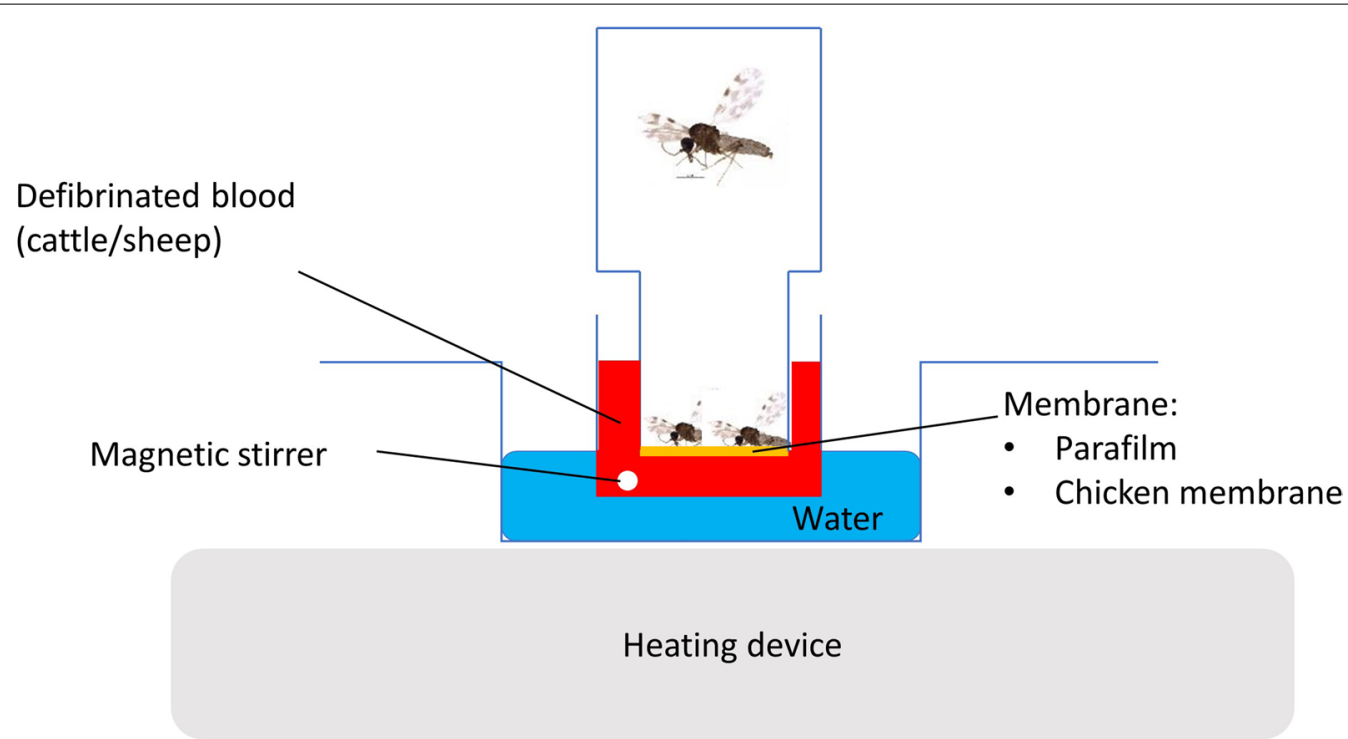

Fig. 3 Blood-feeding system as described by Venter et al. [29] with a feeding chamber and a mounted membrane (Parafilm or chicken membrane), container with blood and magnetic stirrer and a water bath on a magnetic heater

bottle. The bottom of the bottle was replaced by gauze netting. The top of the bottle was cut out and replaced by gauze netting. The blood source was placed on top of the gauze netting. Depending on the availability of field-collected Culicoides, batches of 10-150 C. obsoletus (s.l.) were fed for $2 \mathrm{~h}$ on the systems described above. The number of blood-fed midges was determined after immobilization with $\mathrm{CO}_{2}$.

\section{Statistical analyses}

A $x^{2}$-test and Fisher's exact test were used to determine whether certain developmental parameters differed significantly between the five RCs. One-way ANOVA was used to determine whether significant differences in the average development time of midges occurred between the different RCs, and an unpaired Student's $t$-test was used for two-by-two comparisons. Statistical analyses were done using GraphPad Prism 8.3.0. $P$-values $<0.05$ were considered to be significant.

\section{Results}

\section{Development of subadult life stages}

Oviposition took place 2-14 days after gravid females were collected in the field. A total of 7510 eggs (Fig. 2) were studied under the five RCs described above. Independent of the rearing temperature, large variations in the hatching rates were observed between individual egg batches (0-100\%). Overall, significantly fewer eggs hatched at the lowest temperature condition, namely $14 \%$ at the $20 / 16{ }^{\circ} \mathrm{C}$ gradient (RC4) compared to $60 \%$ and $87 \%$, respectively at $28^{\circ} \mathrm{C}(\mathrm{RC} 1)$ and $24^{\circ} \mathrm{C}(\mathrm{RC} 2)\left(\mathrm{X}^{2}\right.$-test
RC1-RC2-RC4, $\chi^{2}=1315, \quad d f=2, \quad P<0.0001 ; \quad$ Fisher's exact test RC1-RC2, RC1-RC4, RC2-RC4) $(P<0.0001$ in all instances) (Table 1). The addition of dung patches showed no beneficial effect on the egg hatching rates (comparison between RC2 and RC3 and between RC4 and RC5).

After egg hatching, the highest mortality during subadult development occurred during the development from first- to fourth-instar larvae in all treatments and ranged between 85 and 93\%. The addition of horse dung patches significantly increased the larval survival rate from 7 to $16 \%$ in the $20 / 16{ }^{\circ} \mathrm{C}$ RC (Fisher's exact test: $P=0.0452$ ). No increase was observed with the addition of dung patches when rearing was done at $24^{\circ} \mathrm{C}$.

Interestingly, the pupation rate (i.e. number of fourthinstar larvae that pupate) varied significantly between the three temperature treatments $\left(\chi^{2}\right.$-test: $\chi^{2}=61.30, d f=4$, $P<0.0001)$ with a lower pupation rate at the higher temperature condition (74\% in RC1; Fisher's exact test RC1RC2: $P<0.0001)$ and at the lower $20 / 16{ }^{\circ} \mathrm{C}$ day/night temperature gradient $(55.5 \%$ in RC4; Fisher's exact test RC4-RC2: $P<0.0001)$ compared to the $24{ }^{\circ} \mathrm{C}$ condition (98\% in RC2). While the addition of dung patches caused a significant reduction in pupation rate at $24{ }^{\circ} \mathrm{C}$ [98-91\%; (Fisher's exact test RC2-RC3: $P=0.0052$ )], it had no significant effect (Fisher's exact test RC4-RC5: $P=0.1616$ ) under the $20 / 16^{\circ} \mathrm{C}$ day/night condition.

No significant differences were recorded between adult emergence rates under the three temperature conditions $\left(X^{2}\right.$-test: $\left.X^{2}=3.630, \quad d f=2, \quad P=0.1628\right)$. Interestingly, the addition of dung patches increased 
Table 1 Developmental parameters of Culicoides obsoletus (s.I.) subadult life stages under five rearing conditions (RCS)

\begin{tabular}{|c|c|c|c|c|c|c|}
\hline & $\mathrm{RC} 1$ & $\mathrm{RC2}$ & $\mathrm{RC} 3$ & RC4 & RC5 & Total \\
\hline Temperature $\left({ }^{\circ} \mathrm{C}\right)$ & 28 & 24 & 24 & 20/16 Day/night & 20/16 Day/night & \\
\hline Nematodes/algae & $x$ & $x$ & $x$ & $x$ & $x$ & \\
\hline Dung patches & - & - & $x$ & - & $x$ & \\
\hline No. eggs & 1905 & 1748 & 1852 & 903 & 1102 & 7510 \\
\hline Egg hatching rate (\%) & 60 & 87 & 40 & 14 & 8 & 48 \\
\hline No. hatched eggs & 1140 & 1515 & 738 & 129 & 89 & 3611 \\
\hline Larval survival rate ${ }^{\mathrm{a}}(\%)$ & 13 & 15 & 14 & 7 & 16 & 14 \\
\hline No. larvae & 147 & 224 & 104 & 9 & 14 & 498 \\
\hline Pupation rate (\%) & 74 & 98 & 91 & 55.5 & 86 & 88.5 \\
\hline No. pupae & 109 & 220 & 95 & 5 & 12 & 441 \\
\hline Adult emergence rate (\%) & 39 & 50 & 73 & 40 & 83 & 52.5 \\
\hline No. adults & 42 & 109 & 69 & 2 & 10 & 232 \\
\hline No. $\delta^{\star}$ adults & 42 & 83 & 53 & 1 & 5 & 184 \\
\hline No. $q$ adults & 0 & 26 & 16 & 1 & 5 & 48 \\
\hline Sex ratio (đ̋:P) & $1: 0$ & $3: 1$ & $3: 1$ & $1: 1$ & $1: 1$ & \\
\hline $\begin{array}{l}\text { Average overall development time } \\
\text { (days) }\end{array}$ & 26 & 26 & 21 & 33 & 30 & \\
\hline
\end{tabular}

Culicoides subadult life stages were reared in an incubator under $16 / 8 \mathrm{~h}$ light/dark conditions and $80 \%$ relative humidity on $1 \%$ liquid broth agar at the indicated temperature and provided with the additional food sources as indicated in the table

a Survival from first-instar to fourth-instar larvae

the adult emergence rate from 50 to $73 \%$ (Fisher's exact test RC2-RC3: $P=0.0017$ ) at $24{ }^{\circ} \mathrm{C}$ and from 40 to $83 \%$ (Fisher's exact test RC4-RC5: $P=0.1165$ ) under the $20 / 16{ }^{\circ} \mathrm{C}$ condition.

Adults emerged within 1-10 days after pupation. The average overall development time varied significantly between the three temperature conditions [one-way ANOVA RC1-RC2-RC4: $F_{(2,158)}=8.001, R^{2}=0.09197$, $P=0.0005]$ with the longest mean development time of 33 days recorded at $20 / 16{ }^{\circ} \mathrm{C}$ compared to 26 days at $24{ }^{\circ} \mathrm{C}$ and $28{ }^{\circ} \mathrm{C}$ (Fig. 2; Table 1). The addition of dung patches led to significantly shorter average development times at both temperatures [unpaired $t$-test RC2RC3: $t_{(216)}=2.131, P=0.0342$ and RC4-RC5: $t=2.462$, $d f=18, P=0.0242]$.

\section{Sex ratio of emerging adults}

A bias in sex ratio towards the production of males was observed at $28{ }^{\circ} \mathrm{C}$ and $24{ }^{\circ} \mathrm{C}$. Rearing at $28^{\circ} \mathrm{C}$ resulted in the complete absence of emerging females. At $24{ }^{\circ} \mathrm{C}$, the sex ratio improved to a $3: 1 \mathrm{male} /$ female ratio and the emergence of both sexes occurred over the complete eclosion period (Fig. 4). In contrast, lowering the rearing temperature to a $20 / 16{ }^{\circ} \mathrm{C}$ day/night gradient temperature resulted in an equilibrated $1: 1$ sex ratio. Food did not seem to impact the sex ratio, since the addition of dung patches did not affect it (Table 1).

\section{Comparison of blood-feeding methods}

A total of 3714 adult C. obsoletus (s.l.) females were exposed to different blood-feeding systems (cotton pledgets or different membrane types) and different blood sources (sheep or cow blood) to investigate the effect on blood-feeding rates. Overall, engorged midges were obtained in 20 out of 81 (24.7\%) blood-feeding attempts, whereby overall feeding rates per feeding system ranged from 1.8 to $4.7 \%$ (Table 2). C. obsoletus (s.l.) could not be induced to feed through a Parafilm membrane mounted on the blood-feeding system described by Venter et al. [29] or through a collagen membrane mounted on the Hemotek system (Table 2). Blood-feeding rates of, respectively, $3.5 \%$ and $2.7 \%$ were obtained with chicken skin on the blood-feeding system described by Venter et al. [29] and with cotton pledgets. A significantly higher number of Culicoides blood-fed on cattle blood than on sheep blood when it was offered with chicken skin (Fisher's exact test: $P=0.005$ ).

\section{Discussion}

Currently, limited information is available on several aspects of C. obsoletus (s.l.) biology, and no viable laboratory colony exists, which hampers research into this significant vector of bluetongue virus and Schmallenberg virus. The encountered obstacles hindering laboratory colonization include a high mortality rate of field-caught midges, limited knowledge on their 

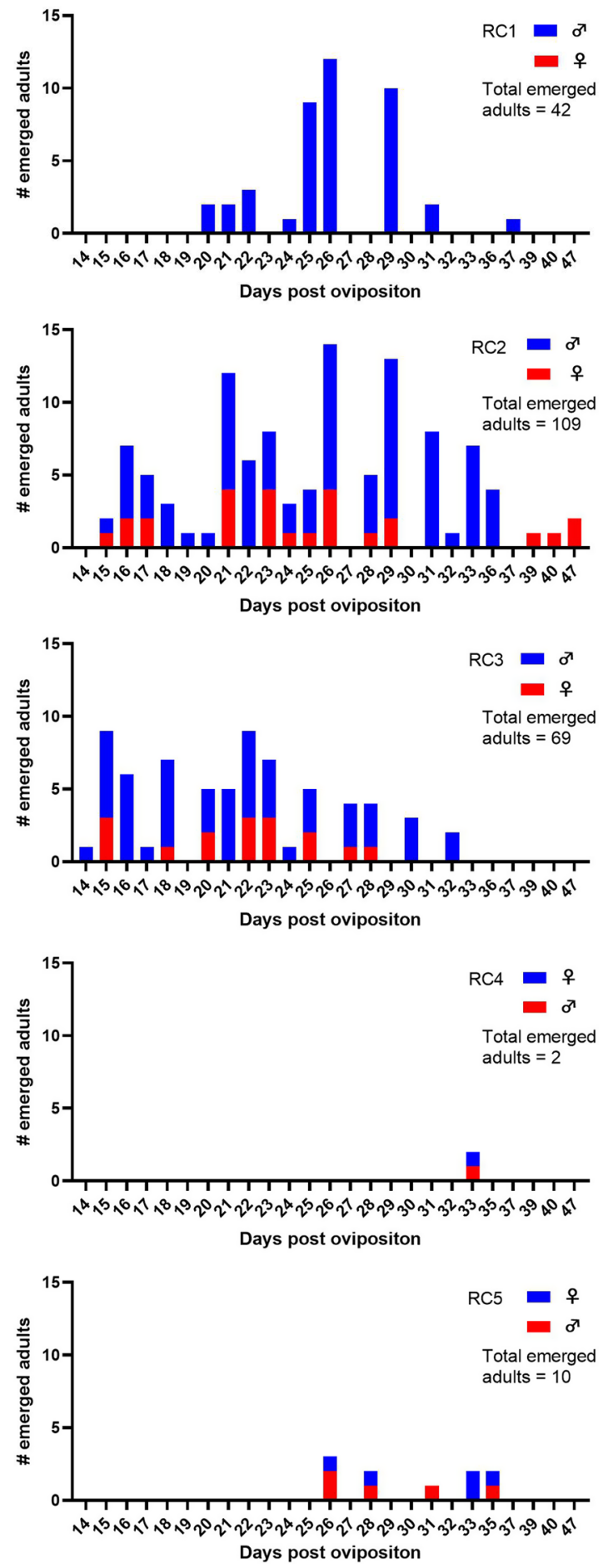

Fig. 4 Emergence patterns of male and female C. obsoletus (s.l.) adults under different rearing conditions $[R C$; ; standard substrate at $28^{\circ} \mathrm{C}(R C 1)$, standard substrate at $24^{\circ} \mathrm{C}(R C 2)$, standard substrate with additional horse dung patches at $24^{\circ} \mathrm{C}(R C 3)$, standard substrate at a $20 / 16^{\circ} \mathrm{C}$ day/night temperature gradient $(R C 4)$, and standard substrate with additional horse dung patches at a $20 / 16^{\circ} \mathrm{C}$ day/night temperature gradient $(R C 5)]$ larval nutrition and larval substrates, and a reluctance of field-collected adults to blood-feed through artificial blood-feeding systems or to mate under captive conditions [15].

In this study, we showed that the life cycle of $C$. obsoletus (s.l.) could be completed in the laboratory from eggs (produced by field-collected females) to progeny adults. After bringing field-collected midges to the laboratory, oviposition could be observed for up to 14 days after collection. This delay in oviposition was also recorded for C. obsoletus by Hill [31] with a period of up to 18 days, although this is in contrast with the results of Barceló et al. [10] who observed an average time of 4 days for oviposition for field-collected, blood-fed females of $C$. obsoletus.

Independent of the RCs, egg hatching rates of individual egg batches ranged from 0 to $100 \%$. There is no clear explanation for this result, but knowledge from other insect species suggests that low hatch rates could be due to lower fertilization rates when females mate with priormated males $[32,33]$, to the fact that the fertility of the eggs can be reduced after multiple egg-laying cycles, or due to an unknown, laboratory-induced phenomenon $[34,35]$.

Interestingly, the comparison of RCs for subadult life stages showed that temperature and larval food sources had an important impact on the outcome. The most prominent effect of rearing at the lowest temperature $\left(20 / 16{ }^{\circ} \mathrm{C}\right.$ gradient) was the low egg hatching rate. Since most other developmental parameters were comparable between the different temperature conditions, this resulted in lower numbers of adults at this temperature. A study by Allingham [36] showed a threshold of $16.5^{\circ} \mathrm{C}$ for the emergence of Culicoides brevitarsis pupae, and this was later confirmed by Bishop et al. [37] who stated that temperatures above $17{ }^{\circ} \mathrm{C}$ would allow populations to develop continuously. These findings could possibly help to explain the low egg hatching rate at the lowest temperature conditions in the present study, as the younger stages may be even more sensitive to suboptimal temperatures. A similar effect has been observed in other Dipteran species such as the yellow dung fly, Scathophaga stercoraria (Diptera: Scathophagidae). A study on this species revealed reduced egg size and reduced offspring survival even at an intermediate temperature of $24{ }^{\circ} \mathrm{C}$ [38].

Other studies reported that higher temperatures resulted in accelerated larval development for different Culicoides species, e.g. C. imicola [12], C. sonorensis [39] and C. brevitarsis [36]. This effect of higher temperature was confirmed by our study since the development time from egg to adult C. obsoletus (s.l.) shortened from 33 days at $20 / 16{ }^{\circ} \mathrm{C}$ to 26 days at $24{ }^{\circ} \mathrm{C}$. However, further 
Table 2 Comparison of effect of different feeding systems and blood source on C. obsoletus (s.l.) blood-feeding rate

\begin{tabular}{|c|c|c|c|c|c|c|}
\hline \multirow[t]{2}{*}{ Feeding system } & \multicolumn{2}{|l|}{ Sheep blood } & \multicolumn{2}{|l|}{ Cattle blood } & \multicolumn{2}{|l|}{ Total } \\
\hline & $\begin{array}{l}\text { No. successful/no. } \\
\text { total meals }\end{array}$ & $\begin{array}{l}\text { No. engorged/total } \\
\text { midges fed (\%) }\end{array}$ & $\begin{array}{l}\text { No. successful/no. } \\
\text { total meals }\end{array}$ & $\begin{array}{l}\text { No. engorged/total } \\
\text { midges fed (\%) }\end{array}$ & $\begin{array}{l}\text { No. successful/no. } \\
\text { total meals }\end{array}$ & $\begin{array}{l}\text { No. engorged/ } \\
\text { total midges } \\
\text { fed (\%) }\end{array}$ \\
\hline Pledgets & $1 / 13$ & 20/665 (3.0) & $1 / 6$ & $4 / 215(1.8)$ & $2 / 19$ & $24 / 880(2.7)$ \\
\hline Collagen & $0 / 5$ & 0/185 (0) & $0 / 5$ & 0/185 (0) & $0 / 10$ & 0/385 (0) \\
\hline Parafilm & $0 / 5$ & 0/155 (0) & $0 / 4$ & 0/160 (0) & $0 / 9$ & 0/315 (0) \\
\hline Chicken skin & $5 / 18$ & 25/1063 (2.35) & $13 / 24$ & $50 / 1071(4.7)$ & $18 / 43$ & $75 / 2134$ (3.5) \\
\hline
\end{tabular}

increasing the temperature to $28{ }^{\circ} \mathrm{C}$ did not result in a shorter development time.

Temperature furthermore affected the sex ratio of emerging adults, with no females found at $28{ }^{\circ} \mathrm{C}$, while $25 \%$ of emerging adults were female at $24{ }^{\circ} \mathrm{C}$, and an equal number of males and females emerged at the $20 / 16^{\circ} \mathrm{C}$ temperature gradient. This seems to suggest that sex is not predetermined at fertilization and that environmental conditions, such as temperature, influence the sex ratio of C. obsoletus (s.l.), although it is not clear at what moment in their development this bias originates. This is in line with another study on C. obsoletus [11] that also showed an extreme bias of the sex ratio towards males and suggested temperature as a possible explanation for this. However, the hypothesis that sex is predetermined but males have a better chance, due to an overall shorter development time compared to that of females, to survive and develop to adulthood under suboptimal conditions cannot be excluded. The effect of temperature on sex determination has also been described in other insect species. In Aedes mosquitoes, high temperature conditions can cause males to develop into morphological females [40]. In Sciara (Diptera: Sciaridae), higher temperatures result in emergence of more females due to changes in genetic imprinting [41].

Other hypotheses, besides a potential influence of temperature, have been put forward to explain biased sex ratios. The effect of insecticides on sex ratio can be ruled out in our RCs as biologically farmed apple (without insecticides) was provided. Various bacterial endosymbionts are known to cause sex ratio distortion in other insect hosts [42]. However, although Lewis et al. [43] screened males and females of various UK species of Culicoides for five common sex ratio-distorting endosymbionts (Cardinium, Wolbachia, Spiroplasma, Arsenophonus and Rickettsia), these endosymbionts were not detected in the C. obsoletus group. In our study, no difference in sex ratio was observed when comparing conditions with or without the addition of horse dung, suggesting that environmental bacteria did not play a major role, whereas temperature did lead to significant differences. However, further studies are needed to improve our understanding of parameters influencing sex ratio distortion in Culicoides.

Besides temperature, we found that food provided to the larvae also impacted subadult development. The addition of dung as an extra food source led to a higher adult emergence rate from pupae, indicating that this additional food resulted in better developed fourth-instar larvae. Dung probably represents a source of bacteria, which are known to be consumed by Culicoides larvae during subadult development [44]. Adding this food source also led to significantly shorter average subadult development at $24{ }^{\circ} \mathrm{C}$ and $20 / 16{ }^{\circ} \mathrm{C}$. The impact of bacteria on larval development should be studied in more detail since it could increase the viability of a future laboratory colony.

These results highlight the difficulty of establishing a laboratory colony of C. obsoletus (s.l.) from field-collected adults. Future studies should aim not only to produce sufficient adults of both sexes to start a colony of C. obsoletus (s.l.) but also to improve blood-feeding and mating methods. C. obsoletus (s.l.) were successfully blood-fed through chicken skin membranes mounted on the bloodfeeding system as described by Venter et al. [29] and via cotton pledgets, but with a very low feeding rate. The difficulty of blood-feeding C. obsoletus in the laboratory is well known, and low blood-feeding rates have been reported using cotton pledgets or different membranes (Parafilm, Nescofilm and chicken skin) mounted on feeding systems. Our overall feeding success rate was lower than those reported in previous studies, which yielded success rates of $6.5-8 \%$ for methods using chicken skin $[17,19], 0.07-6.5 \%$ with Parafilm $[17,19,30]$ and $9-49 \%$ when cotton pledgets were used [28, 30, 45]. Despite previous successful results with Parafilm $[17,19]$, none of our Culicoides could be induced to feed through this membrane. Similar results were found in a recent Italian study that reported feeding rates specific for C. obsoletus (s.l.) as low as $0.07 \%$ with Parafilm [30]. Also, another Culicoides species, C. brevitarsis, could not be successfully blood-fed using the Hemotek system with Parafilm [28]. We were not able to evaluate Nescofilm since this membrane is no longer commercially available. It could 
also be interesting to evaluate blood-feeding of C. obsoletus (s.l.) on embryonated chicken eggs since this led to promising results for Australian Culicoides species [28]. Although we obtained different blood-feeding responses with different systems, we did not observe behaviour during the blood meal, nor differences in behaviour when different membranes or systems were used.

Interestingly, a recent study [46] demonstrated that the orientation of the midges during blood-feeding influences their feeding rate. Higher proportions of $C$. imicola fed when the blood reservoir was offered at the bottom of the feeding chamber compared to when blood was offered from above. It will be interesting to evaluate whether their orientation also influences the blood-feeding of C. obsoletus (s.l.) during future studies.

Since it has been described that Culicoides feeding success can be density dependent [47], the most probable explanation for our low blood-feeding rates is the low number of midges that we used per feeding attempt. Whereas most other studies work with large batches of 300-400 midges [47], we could only attempt to blood feed 10-150 midges at a time, due to the low number of C. obsoletus that were caught in the field. The temperature of the blood could also influence feeding results. Blood was pre-warmed to $37{ }^{\circ} \mathrm{C}$ in accordance with previous studies $[17,19]$. A Swiss study, however, obtained better results when the blood was at $25^{\circ} \mathrm{C}$ [14] than at $37^{\circ} \mathrm{C}$. This is surprising, as we would expect an inverse response since $C$. obsoletus (s.l.) feed on sheep, goats and cattle with a body temperature of around $38.5{ }^{\circ} \mathrm{C}$. Other studies also indicated that the blood-feeding response could be improved if sucrose [28] or ATP [47] were added to the blood. Sucrose and ATP were not used in this study, although these are worth testing in future blood-feeding experiments. However, sucrose has been found to be less than ideal for vector competence experiments $[15,48]$.

\section{Conclusion}

This study provides insight into the subadult development of C. obsoletus (s.l.) and clearly shows the impact and importance of temperature and food sources on larval development. Although lower temperatures $\left(20 / 16{ }^{\circ} \mathrm{C}\right.$ gradient) significantly increased the subadult development time and decreased the egg hatching rate, they did result in an appropriate 1:1 male/female sex ratio. Whether this optimal sex ratio was related to development at low temperature in itself or was rather due to the daily fluctuation in temperature under the $20 / 16{ }^{\circ} \mathrm{C}$ condition deserves further study. Since egg hatching, pupation and adult emergence rates were best at $24{ }^{\circ} \mathrm{C}$, we propose testing a $24 / 20{ }^{\circ} \mathrm{C}$ or a $24 / 16{ }^{\circ} \mathrm{C}$ gradient in future studies. It can furthermore be recommended to use rich media for subadult rearing of C. obsoletus (s.l.) since adding dung as an additional food source significantly increased adult emergence from pupae and shortened the development time. While artificial bloodfeeding with chicken skin and cattle blood provided the best results in our experiments, feeding success was low and these methods require further optimization. Issues related to captive mating of C. obsoletus will also have to be solved since this species is an obligatory swarmer and its potential swarming and mating cues have not yet been identified. Taken together, these results show that RCs need to be further optimized and several obstacles will need to be tackled before a viable laboratory-reared colony of C. obsoletus (s.l.) is within reach.

\section{Acknowledgements}

The authors would like to acknowledge all participating farmers and animal owners for their collaboration. We would also like to thank Brigitte Cay for collecting Culicoides. For help with the daily observation of the larvae, we would like to thank Valerie Redant. For providing Chlamydomonas reinhardtii algae, we would like to thank Quinten Bafort.

\section{Authors' contributions}

CVDE: conceptualization, methodology, software, formal analysis, investigation, data curation, writing —original draft preparation, writing-review and editing, visualization, validation. CS: conceptualization, methodology, software, formal analysis, investigation, data curation, writing —original draft preparation, writing — review and editing, visualization, validation. SM: conceptualization, writing — review and editing. NDR: conceptualization, methodology, formal analysis, resources, data curation, writing —original draft preparation, writing — review and editing, supervision, project administration, funding acquisition.

\section{Funding}

This study was funded by the Belgian Federal Public Service of Health, Food Chain Safety and Environment through contract RT 15/3 LUMPY SKIN 1.

Availability of data and materials

Not applicable.

\section{Declarations}

Ethics approval and consent to participate

One-day-old euthanized chickens were kindly provided by Avian virology and immunology, Sciensano, following national and European regulations (procedure agreement 101105-02)

Consent for publication

Not applicable.

Competing interests

None of the authors declare a conflict of interest that could bias or affect the content of this paper.

Received: 28 January 2021 Accepted: 11 May 2021

Published online: 05 June 2021

\section{References}

1. De Deken G, Madder M, Deblauwe I, De Clercq K, Fassotte C, Losson B, et al. Vector monitoring at Belgian outbreak sites during the bluetongue epidemic of 2006. Prev Vet Med. 2008;87:64-73. 
2. Carolina A, Jung L, Chueca M, Segui B, Version D. Big data-modelling of midges in Europa using machine learning techniques and satellite imagery. NKVet Symp. 2017.

3. Cuéllar AC, Kjær LJ, Kirkeby C, Skovgard H, Nielsen SA, Stockmarr A, et al. Spatial and temporal variation in the abundance of Culicoides biting midges (Diptera: Ceratopogonidae) in nine European countries. Parasites Vectors. 2018;11:112.

4. De Regge N, De Deken R, Fassotte C, Losson B, Deblauwe I, Madder M, et al. Culicoides monitoring in Belgium in 2011: analysis of spatiotemporal abundance, species diversity and Schmallenberg virus detection. Med Vet Entomol. 2015:29:263-75.

5. Vanbinst T, Vandenbussche F, Vandemeulebroucke E, De Leeuw I, Deblauwe I, De Deken G, et al. Bluetongue virus detection by real-time RT-PCR in Culicoides captured during the 2006 epizootic in Belgium and development of an internal control. Transbound Emerg Dis. 2009:56:170-7.

6. Purse BV, Carpenter S, Venter GJ, Bellis G, Mullens BA. Bionomics of temperate and tropical Culicoides midges: knowledge gaps and consequences for transmission of Culicoides-borne viruses. Annu Rev Entomol. 2015;60:373-92

7. Mellor PS, Boorman J, Baylis M. Culicoides biting midges: their role as arbovirus vectors. Annu Rev Entomol. 2000;45:307-40.

8. Vaughan JA, Turner EC. Seasonal microdistribution of immature Culicoides variipennis (Diptera: Ceratopogonidae) at Saltville, Virginia. J Med Entomol. 1987:24:340-6.

9. Linley JR. Growth and survival of Culicoides melleus larvae (Diptera: Ceratopogonidae) on four prey organisms. J Med Entomol. 1985;22:178-89.

10. Barcelo C, Miranda MA. Bionomics of livestock-associated Culicoides (biting midge) bluetongue virus vectors under laboratory conditions. Med Vet Entomol. 2018;32:216-25.

11. Boorman J. Rearing Culicoides obsoletus (Diptera, Ceratopogonidae) on agar cultures of nematodes. Prog Clin Biol Res. 1985;178:229-31.

12. Veronesi E, Venter GJ, Labuschagne K, Mellor PS, Carpenter S. Life-history parameters of Culicoides (Avaritia) imicola Kieffer in the laboratory at different rearing temperatures. Vet Parasitol. 2009;163:370-3.

13. Carpenter S, Veronesi E, Mullens B, Venter G. Vector competence of Culicoides for arboviruses: three major periods of research, their influence on current studies and future directions. OIE Rev Sci Tech. 2015;34:97-112.

14. Paslaru Al, Mathis A, Torgerson P, Veronesi E. Vector competence of pre-alpine Culicoides (Diptera: Ceratopogonidae) for bluetongue virus serotypes 1, 4 and 8. Parasites Vectors. 2018;11:1-12.

15. Venter GJ, Paweska JT, Lunt H, Mellor PS, Carpenter S. An alternative method of blood-feeding Culicoides imicola and other haematophagous Culicoides species for vector competence studies. Vet Parasitol. 2005;131:331-5.

16. Veronesi E, Antony F, Gubbins S, Golding N, Blackwell A, Mertens PPC, et al. Measurement of the infection and dissemination of bluetongue virus in Culicoides biting midges using a semi-quantitative RT-PCR assay and isolation of infectious virus. PLOS ONE. 2013:8:1-8.

17. Goffredo M, Romeo G, Monaco F, Di Gennaro A, Savini G. Laboratory survival and blood feeding response of wild-caught Culicoides obsoletus complex (Diptera: Ceratopogonidae) through natural and artificial membranes. Vet Ital. 2004:40:282-5.

18. Carpenter S, Lunt HL, Arav D, Venter GJ, Mellor PS. Oral susceptibility to bluetongue virus of Culicoides (Diptera: Ceratopogonidae) from the United Kingdom. J Med Entomol. 2006;43:73-8.

19. Barber J, Harrup LE, Silk R, Veronesi E, Gubbins S, Bachanek-Bankowska K, et al. Blood-feeding, susceptibility to infection with Schmallenberg virus and phylogenetics of Culicoides (Diptera: Ceratopogonidae) from the United Kingdom. Parasites Vectors. 2018;11:1-13.

20. Pagès N, Talavera S, Verdún M, Pujol N, Valle M, Bensaid A, et al. Schmallenberg virus detection in Culicoides biting midges in Spain: first laboratory evidence for highly efficient infection of Culicoides of the obsoletus complex and Culicoides imicola. Transbound Emerg Dis. 2018;65:1-6.

21. Sohier C, Deblauwe I, De Deken R, Madder M, Fassotte C, Losson B, et al. Longitudinal monitoring of Culicoides in Belgium between 2007 and 2011: local variation in population dynamics parameters warrant cautious use of monitoring data. Parasites Vectors. 2018;11:1-9.

22. Mathieu B, Cêtre-Sossah C, Garros C, Chavernac D, Balenghien T, Carpenter $S$, et al. Development and validation of IIKC: an interactive identification key for Culicoides (Diptera: Ceratopogonidae) females from the Western Palaearctic region. Parasites Vectors. 2012;5:137.

23. Manley R, Harrup LE, Veronesi E, Stubbins F, Stoner J, Gubbins S, et al. Testing of UK populations of Culex pipiens L. for Schmallenberg virus vector competence and their colonization. PLoS ONE. 2015:10:0134453.

24. Veronesi E, Paslaru A, Silaghi C, Tobler K, Glavinic U, Torgerson P, et al. Experimental evaluation of infection, dissemination, and transmission rates for two West Nile virus strains in European Aedes japonicus under a fluctuating temperature regime. Parasitol Res. 2018;117:1925-32.

25. Kaufmann C, Mathis A, Vorburger C. Sugar-feeding behaviour and longevity of European Culicoides biting midges. Med Vet Entomol. 2015:29:17-25.

26. Gorman DS, Levine RP. Cytochrome F and plastocyanin: their sequence in the photosynthetic electron transport chain of Chlamydomonas reinhardis. Proc Natl Acad Sci USA. 1965;54:1665-9.

27. Mullens BA, Velten RK. Rearing Culicoides variipennis sonorensis (Diptera, Ceratopogonidae) on agar and nematodes. J Med Entomol. 1994;31:175-7.

28. Van der Saag M, Nicholas A, Ward M, Kirkland P. Evaluation of in vitro methods for assessment of infection of Australian Culicoides spp. with bluetongue viruses. Vet Ital. 2015;51:335-43.

29. Venter GJ, Hill E, Pajor IT, Nevill EM. The use of a membrane feeding technique to determine the infection rate of Culicoides imicola (Diptera, Ceratopogonidae) for 2 bluetongue virus serotypes in South Africa. Onderstepoort J Vet Res. 1991;58:5-9.

30. Federici V, Goffredo M, Mancini G, Quaglia M, Santilli A, Di Nicola F, et al. Vector competence of Italian populations of Culicoides for some bluetongue virus strains responsible for recent Northern African and European outbreaks. Viruses. 2019;11:941.

31. Hill MA. The life-cycle and habits of Culicoides impunctatus Goetghebuer and Culicoides obsoletus Meigen, together with some observations on the life-cycle of Culicoides odibilis Austen, Culicoides pallidicornis Kieffer, Culicoides cubita lis Edwards and Culicoides chiopterus Meigen. Ann Trop Med Parasitol. 1947;22(41):55-115.

32. Lauwers $\mathrm{K}$, Van Dyck $H$. The cost of mating with a non-virgin male in a monandrous butterfly: experimental evidence from the speckled wood Pararge aegeria. Behav Ecol Sociobiol. 2006;60:69-76.

33. Perez-Staples D, Aluja M, Macías-Ordóñez R, Sivinski J. Reproductive trade-offs from mating with a successful male: the case of the tephritid fly Anastrepha obliqua. Behav Ecol Sociobiol. 2008;62:1333-40.

34. Erram D, Burkett-Cadena N. Laboratory Rearing of Culicoides stellifer (Diptera: (eratopogonidae), a suspected vector of orbiviruses in the United States. J Med Entomol. 2020;57:25-32.

35. Davis EL, Butler JF, Roberts RH, Reinert JF, Kline DL. Laboratory blood feeding of Culicoides mississippiensis (Diptera: Ceratopogonidae) through a reinforced silicone membrane. J Med Entomol. 1983;20:177-82.

36. Allingham PG. Effect of temperature on late immature stages of Culicoides brevitarsis (Diptera: Ceratopogonidae). J Med Entomol. 1991:28:878-81.

37. Bishop AL, McKenzie HJ, Barchia IM, Harris AM. Effect of temperature regimes on the development, survival and emergence of Culicoides brevitarsis Kieffer (Diptera: Ceratopogonidae) in bovine dung. Aust J Entomol. 1996:35:361-8

38. Blanckenhorn WU. Temperature effects on egg size and their fitness consequences in the yellow dung fly Scathophaga stercoraria. Evol Ecol. 2000;14:627-43.

39. Lysyk TJ, Danyk T. Effect of temperature on life history parameters of adult Culicoides sonorensis (Diptera: Ceratopogonidae) in relation to geographic origin and vectorial capacity for bluetongue virus. J Med Entomol. 2007:44:741-51.

40. Horsfall WR, Anderson JF. Suppression of male characteristics of mosquitoes by thermal means. Science. 1961:133:1830.

41. Sanchez L. Sex-determining mechanisms in insects. Int J Dev Biol. 2008:52:837-56.

42. Murray RL, Herridge EJ, Ness RW, Bussière LF. Are sex ratio distorting endosymbionts responsible for mating system variation among dance flies (Diptera: Empidinae)? PLoS ONE. 2017;12:1-15.

43. Lewis SE, Rice A, Hurst GDD, Baylis M. First detection of endosymbiotic bacteria in biting midges Culicoides pulicaris and Culicoides punctatus, important Palaearctic vectors of bluetongue virus. Med Vet Entomol. 2014:28:453-6. 
44. Mullen G, Hribar L. Biology and feeding behavior of ceratopogonid larvae (Diptera: Ceratopogonidae) in North America. Bull Soc Vector Ecol. 1988;13:60-81.

45. Carpenter S, McArthur C, Selby R, Ward R, Nolan DV, Luntz AJM, et al. Experimental infection studies of UK Culicoides species midges with bluetongue virus serotypes 8 and 9. Vet Rec. 2008;163:589-92.

46. de Beer CJ, Boikanyo SNB, Venter GJ. Assessment of the Hemotek ${ }^{\circledR}$ system for the in vitro feeding of field-collected Culicoides imicola (Diptera: Ceratopogonidae) in South Africa. Med Vet Entomol. 2020;35:177-86 (Epub ahead of print. PMID: 32990991).

47. Blackwell A, Mellor PS, Mordue W. Laboratory feeding of Culicoides impunctatus (Diptera: Ceratopogonidae) through natural and artificial membranes. J Med Entomol. 1994;31:302-5.
48. Mellor PS, Boned J, Hamblin C, Graham S. Isolations of African horse sickness virus from vector insects made during the 1988 epizootic in Spain. Epidemiol Infect. 1990;105:447-54.

\section{Publisher's Note}

Springer Nature remains neutral with regard to jurisdictional claims in published maps and institutional affiliations.
Ready to submit your research? Choose BMC and benefit from:

- fast, convenient online submission

- thorough peer review by experienced researchers in your field

- rapid publication on acceptance

- support for research data, including large and complex data types

- gold Open Access which fosters wider collaboration and increased citations

- maximum visibility for your research: over $100 \mathrm{M}$ website views per year

At BMC, research is always in progress.

Learn more biomedcentral.com/submissions 